\title{
Moldes de ABS Construídos pelo Processo de Modelagem por Fusão e Deposição para Injeção de PP e PEBD
}

\author{
José A. Foggiatto \\ CIMJECT, UFSC e NUFER, CEFET-PR \\ Carlos H. Ahrens, Gean V. Salmoria \\ CIMJECT, UFSC \\ Alfredo T. N. Pires \\ POLIMAT, UFSC
}

Resumo: Os processos de prototipagem rápida (Rapid Prototyping - RP) e ferramental rápido (Rapid Tooling - RT) surgiram para reduzir os tempos de desenvolvimento de produtos na fase de projeto diminuindo a necessidade de retrabalhos e, conseqüentemente, antecipando a entrada de novos produtos no mercado. Neste trabalho foi utilizada uma das tecnologias de prototipagem rápida, denominada Modelagem por Fusão e Deposição (FDM), na construção de moldes em ABS com o objetivo de investigar sua aplicação na moldagem por injeção de termoplásticos. Amostras das peças injetadas foram submetidas a ensaios de difração de raios X, dureza Shore D e tração. Os resultados mostraram a viabilidade de fabricar pequenos lotes de peças em PEBD e PP com propriedades mecânicas bastante similares às encontradas em peças moldadas em moldes metálicos.

Palavras-chave: Prototipagem rápida, modelagem por fusão e deposição, ferramental rápido.

\section{PP and LDPE Injection in ABS Molds Built with Fused Deposition Modeling}

Abstract: Rapid Prototyping and Rapid Tooling are aimed at reducing the development time of products in the design phase by minimizing re-workings and, consequently, reducing the time to launch new products. In this work one of the technologies of rapid prototyping, called Fused Deposition Modeling (FDM), was used in the construction of ABS molds with the objective of investigating its application in the injection molding of thermoplastics. Specimens of the molded parts were characterized with X-ray diffraction, Shore D hardness and tensile tests. The results demonstrated the viability to manufacture small batches of LDPE and PP parts with mechanical properties similar to those molded parts in metallic molds.

Keywords: Rapid prototyping, fused deposition modeling, rapid tooling.

\section{Introdução}

O termo prototipagem rápida se refere a um conjunto de tecnologias de fabricação capaz de construir rapidamente objetos tridimensionais pela adição sucessiva de finas camadas. No segmento de projeto de peças de termoplásticos, algumas destas tecnologias têm sido também empregadas para a construção de moldes para os mais variados processos de moldagem, sendo então denominadas de técnicas de ferramental rápido ${ }^{[1]}$.

Em se tratando da moldagem por injeção de termoplásticos, uma das vantagens atribuídas ao uso de moldes fabricados através de processos de prototipagem rápida é a obtenção de lotes de peças injetadas no material de produção, dispensando a necessidade da usinagem de cavidades piloto, reduzindo assim o tempo e o custo do projeto da peça.
As técnicas de ferramental rápido foram originariamente desenvolvidas utilizando-se moldes de resina epoxiacrilato feitos através da tecnologia de Estereolitografia (SL), os quais permitem a injeção de um número reduzido de peças devido a sua baixa resistência mecânica ${ }^{[2]}$. A Sinterização Seletiva a Laser (SLS) é outro processo que tem sido bastante utilizado, pois apresenta a vantagem de produzir moldes metálicos que possuem uma boa resistência mecânica, porém com limitações relativas ao acabamento nas superfícies da cavidade do molde ${ }^{[3]}$.

$\mathrm{O}$ processo de prototipagem rápida, denominado Modelagem por Fusão e Deposição (FDM - Fused Deposition Modeling) utiliza um cabeçote extrusor de filetes para construir objetos pela fusão e deposição adjacente de filetes em diversos materiais, principalmente o ABS (Figura 1). Embora o processo FDM tenha tido grande aceitação no mer-

Autor para correspondência: Carlos H. Ahrens, CIMJECT, UFSC, Campus Universitário Trindade, CEP: 88040-900, Florianópolis, SC. E-mail: pires@cfm.ufsc.br 


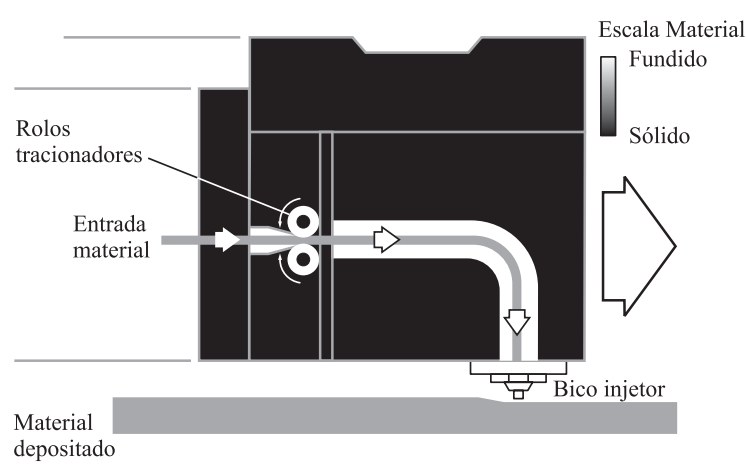

Figura 1. Cabeçote extrusor de filetes ${ }^{[6]}$.

cado por possuir preços competitivos, produzir peças com boas propriedades mecânicas e por ser de fácil instalação ${ }^{[4]}$, o uso dessa tecnologia para moldes de injeção é recente, limitando-se a poucos trabalhos como o de Masood et al[5], que desenvolveu um novo material para confecção de moldes, composto de uma mistura de pó metálico e um polímero, pois o autor acreditava que o ABS não teria propriedades mecânicas e térmicas desejáveis para utilização na construção de moldes para injeção. Esse molde possibilitou a injeção de 50 peças em PEBD, 25 peças em ABS e apresentou problemas de delaminação nas bordas.

Este trabalho tem como objetivo investigar a viabilidade de injetar termoplásticos em moldes de ABS fabricados por Modelagem por Fusão e Deposição (FDM), buscando obter peças com propriedades semelhantes às injetadas em moldes em aço.

\section{Experimental}

Os experimentos foram realizados em duas etapas. Em um primeiro estudo de caso foi fabricado um molde de ABS utilizando uma geometria simples (Figura 2) e parâmetros de construção padrão (altura da camada $=0,254 \mathrm{~mm}$ e espessura do filete $=0,508 \mathrm{~mm}$ ) sem acabamento nas superfícies. Por não apresentarem adesividade com o ABS foram injetadas peças em PEBD e PP.

No segundo estudo de caso foram construídos dois moldes, sendo um de ABS e outro de aço. Foi escolhida a geometria de um corpo de prova de tração ASTM D 638m tipo

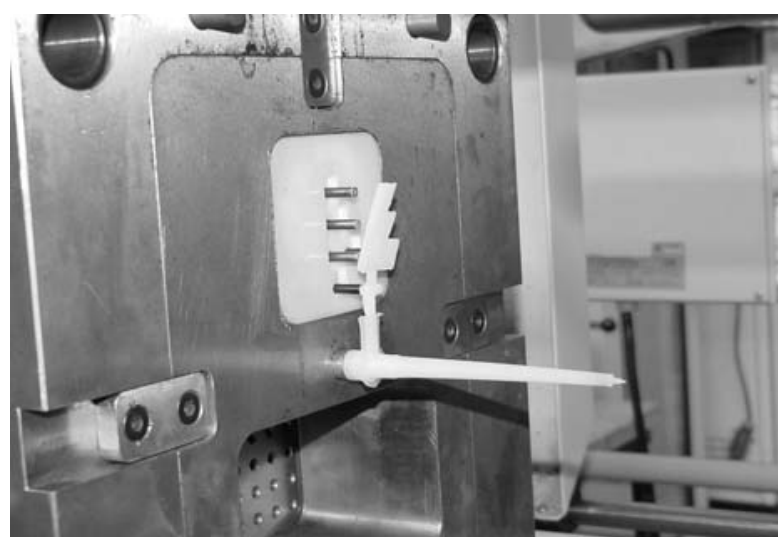

Figura 2. Peça injetada no estudo de caso 1

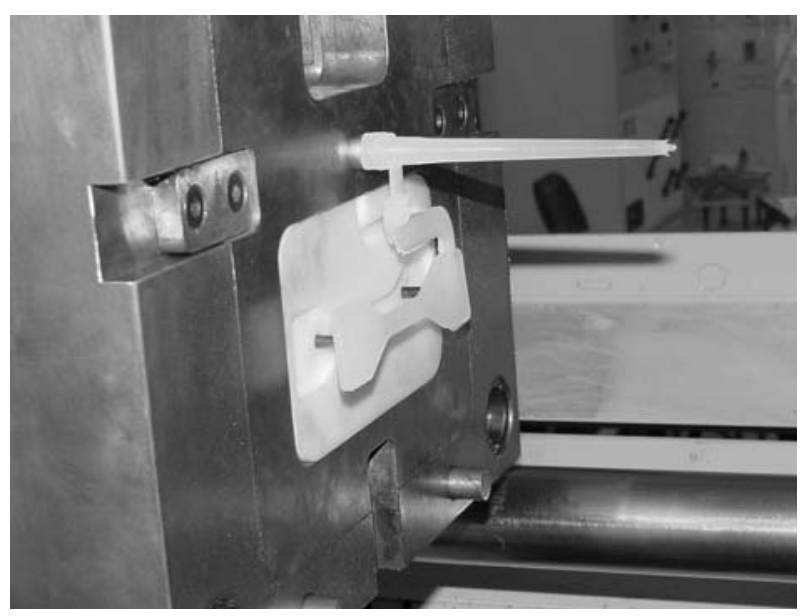

Figura 3. Molde de ABS para injeção de corpos de prova do estudo de caso 2

IV para uso nas investigações sobre a estrutura e as propriedades mecânicas da peça injetada (Figura 3). Os parâmetros de construção do molde de ABS foram alterados de modo a aumentar a coesão entre filetes melhorando o seu acabamento superficial e a resistência mecânica (altura da cama$\mathrm{da}=0,178 \mathrm{~mm}$ e espessura do filete $=0,305 \mathrm{~mm}$ ). A parte plana do molde fixo foi lixada para avaliar o efeito desse processo sobre a superfície das peças injetadas.

Foram realizadas micrografias em um microscópio eletrônico de varredura (MEV) Philips XL-30 para comprovar se os valores de espessura dos filetes configurados na máquina de prototipagem eram reproduzidos nas superfícies dos moldes.

No processo de injeção do PP H-301(Brasken) utilizaramse condições específicas de moldagem com o intuito de preservar a integridade do molde (temperaturas nas zonas de aquecimento $=170,165,160,155$ e $150^{\circ} \mathrm{C}$, pressão de injeção $=270 \mathrm{Bar}$, pressão de recalque $=160 \mathrm{Bar}$, tempo de recalque $=7 \mathrm{~s}$, velocidade de injeção $=120 \mathrm{~mm} / \mathrm{s}$ ). Os ajustes dos parâmetros de injeção foram realizados utilizando-se o método de "Preenchimento Incompleto"[7]. Para que fosse possível monitorar a temperatura do inserto nas proximidades da sua superfície, foi instalado um termopar do tipo K na região central da cavidade em forma de corpo-de-prova. Os dados foram coletados com a ajuda de um sistema de aquisição de dados TC-08 da Pico Technology Limited.

Amostras das peças injetadas nos moldes de ABS e de aço foram submetidas a análises de difração de raios $\mathrm{X}$, dureza Shore D e ensaios de tração. Para a realização das análises de difração de raios X utilizou-se um difratômetro Philips modelo X'PERT MPD com radiação K $\alpha$ do cobre, para os ensaios de dureza Shore D e de tração utilizaram-se um durômetro WULTEST SD300 e um equipamento EMIC, respectivamente.

\section{Resultados e Discussão}

O primeiro estudo verificou a possibilidade de injetar peças em um molde de ABS identificando as possíveis dificuldades. Foram injetadas 30 peças em PEBD reciclado e 120 peças em PP. As peças obtidas no processo de injeção apre- 


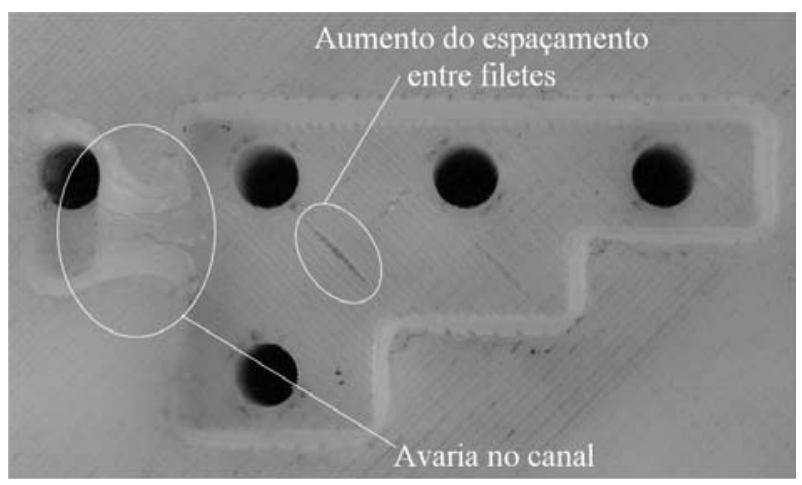

Figura 4. Aspecto da cavidade após a injeção

sentaram em suas superfícies marcas relativas ao espaçamento entre filetes, resultado dos parâmetros de construção utilizados na fabricação do molde. No final do experimento as superfícies dos moldes apresentavam maior espaçamento entre os filetes (trincas) e o canal de injeção ficou avariado devido a ação combinada de temperatura e pressão (Figura 4).

A Figura 5 mostra micrografias de duas superfícies: uma construída com parâmetros de construção padrão (A) e outra com os parâmetros refinados (B). Observou-se que o molde fabricado com o parâmetro padrão apresentou $0,485 \mathrm{~mm}$ para a espessura do filete, bem próximo do valor ajustado $(0,508$ $\mathrm{mm}$ ), enquanto que o molde construído com parâmetros refinados apresentou $0,324 \mathrm{~mm}$ (valor ajustado $=0,305 \mathrm{~mm}$ ). A construção do inserto com valores de espaçamento entre file-
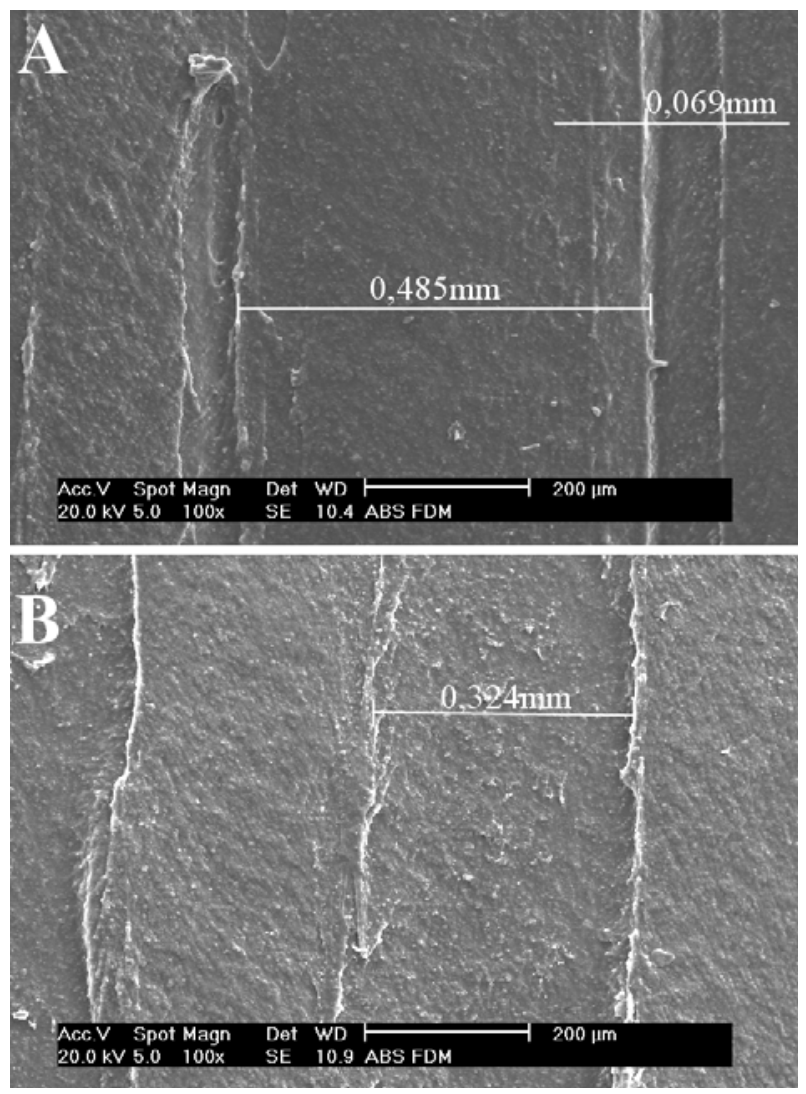

Figura 5. Micrografias: (A) Parâmetro de construção padrão - (B) Parâmetro de construção refinado. tes (gap) menores ou iguais a zero permite uma maior adesão entre os filetes. Isso foi constatado ao observar que o espaçamento entre filetes adjacentes de $0,069 \mathrm{~mm}$ (indicado na micrografia A da figura 5) tornou essa superfície muito mais suscetível ao aumento do espaçamento entre filetes do que a segunda, onde esse espaçamento não existe $(g a p=0)$.

$\mathrm{O}$ segundo estudo de caso confirmou que a diminuição dos parâmetros de construção do molde melhorou as características mecânicas e minimizou a ocorrência de trincas nas superfícies. No final do processo de injeção observou-se o arredondamento dos cantos do canal, provocado por uma deformação a quente e ainda um pequeno descolamento na superfície do canal de injeção devido, provavelmente, a sua geometria semi-circular não permitir boa adesão entre as camadas. Foram injetadas 250 peças em PP com melhora na qualidade das superfícies, embora tenha ficado evidente a necessidade de incluir uma etapa de acabamento nas superfícies da cavidade do molde de ABS para eliminar as marcas inerentes ao processo construtivo.

As peças injetadas nos moldes de ABS apresentam uma maior quantidade de fase cristalina se comparadas às peças injetadas nos moldes de aço, como pode ser observado no halo sob os picos dos difratogramas da Figura 4.
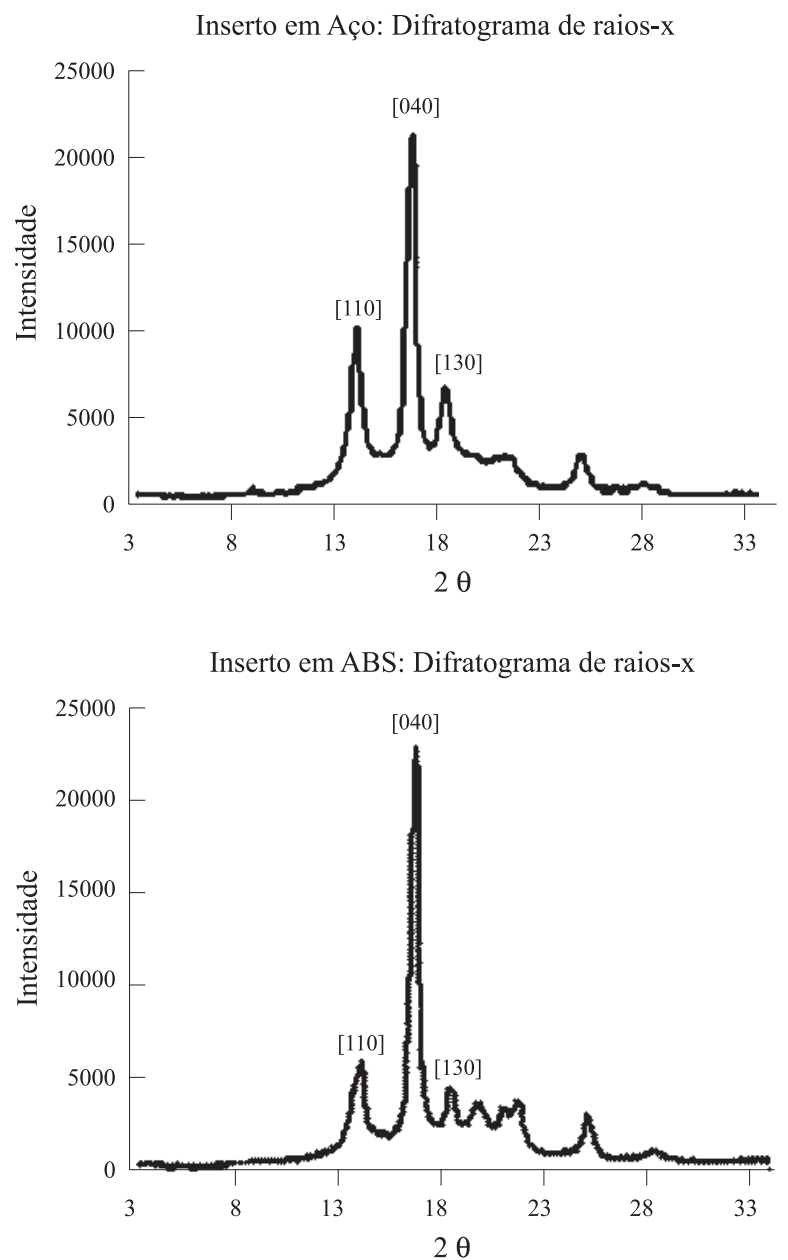

Figura 6. Difratogramas de corpos-de-prova em PP injetados em insertos de aço e ABS 
Tabela 1. Valores médios de módulo de elasticidade, resistência à tração e de dureza Shore D para corpos-de-prova em PP injetados em moldes de aço e ABS.

\begin{tabular}{ccccc}
\hline Corpo de prova em PP & $\begin{array}{c}\text { Módulo de } \\
\text { elasticidade } \\
\text { (Mpa) }\end{array}$ & $\begin{array}{c}\text { Resistência } \\
\text { à tração } \\
\text { (MPa) }\end{array}$ & $\begin{array}{c}\text { Dureza } \\
\text { Shore D }\end{array}$ \\
\hline $\begin{array}{c}\text { Molde } \\
\text { de aço }\end{array}$ & Valor médio & 698 & 27,8 & 69,4 \\
& Desvio padrão & 29 & 0,27 & 0,96 \\
\hline $\begin{array}{c}\text { Molde } \\
\text { de ABS }\end{array}$ & Valor médio & 641 & 27,5 & 68,3 \\
\hline
\end{tabular}

A principal fase cristalina do PP (fase alfa) é monoclínica ( $a=6,65 \AA, b=20,96 \AA, c=6,5 \AA$ ), enquanto que a menos comum (fase beta) é hexagonal ( $a=b=2,74 \AA, c=6,35 \AA)$. A relação entre a orientação do PP nos eixos a e b para a fase cristalina alfa pode ser determinada pela razão das intensidades no plano [040] (pico em $2 \theta=16,7^{\circ}$ ) e no plano [110] (pico em $\left.2 \theta=13,9^{\circ}\right)^{[8]}$ mostrados na Figura 6 . Diversos valores para essa razão são encontrados na literatura para uma mistura isotrópica de cristalitos de PP, como Addink \& Beintema $(1961)^{[9]}$ que fornecem o valor de 0,54 e Rybnikar (1989) $)^{[10]}$ que descreve esses valores como compreendidos entre 0,67 e 0,77. A morfologia e a orientação dos cristais do PP depende muito das condições de cristalização e de moldagem. A

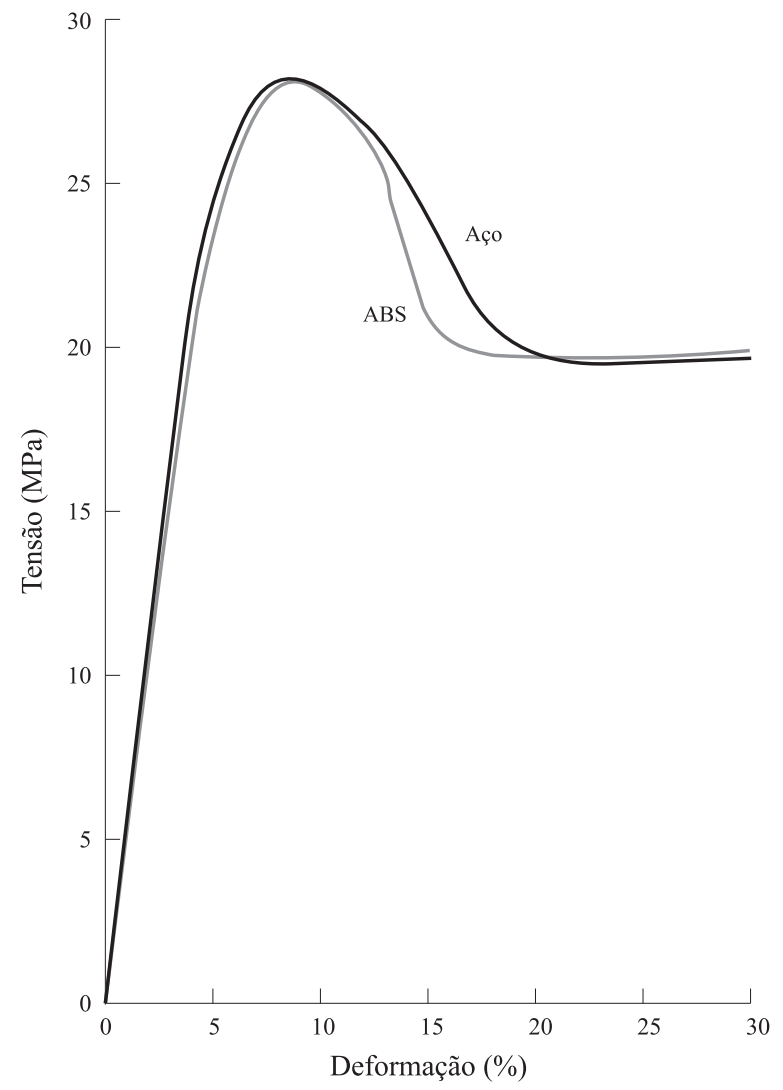

Figura 7. Diagrama Tensão/Deformação de corpos-de-prova em PP injetados a $170{ }^{\circ} \mathrm{C}$ em moldes de aço e de ABS. razão encontrada para o PP injetado em moldes de ABS e de aço foi de 0,225 e 0,472 respectivamente. Esses resultados sugerem uma grande orientação dos cristais de PP injetados em moldes de ABS.

Foram realizados ensaios de dureza e de tração (Tabela 1) para investigar se as propriedades mecânicas das peças injetadas nos moldes de aço e de ABS teriam sido afetadas pela diferença de orientação em sua estrutura. As amostras revelaram valores médios de dureza bastante próximos (entre 68 e 69 Shore D), sendo estes um pouco inferiores aos valores comumente encontrados para peças injetadas em PP (71 a 73 Shore D) ${ }^{[11]}$.

Os ensaios de tração mostraram que o limite de resistência à tração e o módulo de elasticidade, para os corpos-de-prova injetados nos dois tipos de moldes, tiveram valores bastante próximos (Figura 7) sugerindo não existir diferenças marcantes nas propriedades mecânicas das peças injetadas em moldes de ABS se comparadas às injetadas em moldes de aço. Observou-se ainda, que as regiões de escoamento tiveram comportamentos diferenciados, este fato pode estar ligado a diferença de cristalinidade e orientação detectada nas análises de difração de raios X.

\section{Conclusões}

Pode-se afirmar que a moldagem por injeção de termoplásticos em moldes de ABS mostrou-se viável para a produção de pequenos lotes de peças com geometrias simples em PEBD e PP. Os estudos em corpos-de-prova de PP injetados em ABS revelaram pequenas diferenças de orientação e de cristalinidade, no entanto suas propriedades mecânicas não foram afetadas, sendo estas similares às injetadas em moldes convencionais. Os resultados dessa investigação serão utilizados para o aperfeiçoamento desse processo visando o melhoramento na superfície do molde através do uso de técnicas como lixamento e recobrimento. Espera-se que o recobrimento permita ampliar a gama de termoplásticos passíveis de injeção sem a ocorrência de defeitos ocasionados pela adesividade entre peça e molde.

\section{Agradecimentos}

Os autores agradecem ao CEFET-PR e à CAPES-PICD pelo suporte financeiro para realização deste trabalho.

\section{Referências Bibliográficas}

1. Gomide, R. B. - "Fabricação de Componentes Injetados com Uso de Insertos de Resina Termofixa Produzidos por Estereolitografia”, Dissertação de Mestrado, Universidade Federal de Santa Catarina, Brasil, (2000).

2. Dickens, P. M. - "Rapid tooling techniques", in Proceedings of EuroMold'99 Conference, RP's Strategic Benefits and Risks, Frankfurt, Germany, (1999).

3. King, D. \& Tansey, T. - "Alternative materials for rapid tooling", Journal of Materials Processing Technology., 121, p. 313-317 (2002). 
4. Stratasys Inc. - "FDM 2000 Manual”, Stratasys Document no 105215-0001 Rev. 5B, Eden Prairie, USA, (2001).

5. Masood, S.H.; Song W.Q.; Hodgkin, J.K.; Friedl, C. "Rapid Tooling for Injection Moulding using Fused Deposition Modelling", in Annals of 57th ANTEC Annual Technical Conference, New York, USA, (1999).

6. Stratasys Inc. "FDM 2000 Manual", Stratasys Document no 105215-0001 Rev. 5B, Eden Prairie, USA (2001).

7. Barry, C.; Boothroyd, P.; Lai, F.; Nunn, R.E.; Orroth, S.A.; Schott N.R.; "Short Shot Method of Injection Molding. Plastics Processing”, Laboratory Syllabus, University of Massachusetts, Lowell-Plastic Engineering Department, $6^{\circ}$ ed., p. 61, USA, (1995).

8. Velasco, J.I.; Morhain, C.; Martínez, A.B.; RodríguezPérez, M.A.; De Saja, J.A.; "The effect of filler type, morphology and coating on the anisotropy and microstructure heterogeneity of injection-moulded discs of polypropylene filled with aluminium and magnesium hydroxides. Part 1. A wide-angle X-ray diffraction study", Polymer, 43, p.6805-6811, (2002).

9. Addink, E.J., Beintema J., "Polymorphism of crystalline polypropylene” Polymer; 2, p.185-193, (1961).

10. Rybnikar, F. "Orientation in composite of polypropylene and talc", Journal of Applied Polymer Science, 38:8, p.1479-1490, (1989).

11. Ahrens, C. H., Lafratta, F. H., Foggiatto, J. A., Salmoria, g., Volpato, N., Ferreira, A. C. "Estudo da Estrutura e Propriedades de Peças de PP Moldados por Injeção em Ferramentas de Prototipagem" In: XV Congresso Brasileiro de Engenharia e Ciência dos Materiais, Natal-RN (2002).

Enviado: $13 / 04 / 04$ Reenviado: $14 / 07 / 04$ Aprovado: 13/08/04 